\title{
EMPAQUETADO GENÉRICO: \\ RETOS Y DESAFÍOS \\ PARA EL DERECHO MARCARIO
}

\author{
MABEL CÁNDANO PÉREZ*
}

\section{INTRODUCCIÓN}

Durante largos años las polémicas existentes entre la salud pública y la propiedad intelectual han sido objeto de diversos argumentos, lo cual genera que se hayan realizado varios estudios sobre el tema. El debate principal se ha concentrado en las investigaciones sobre las patentes farmacéuticas, si bien la salud pública también presenta conflictos con el derecho de marcas. Estas tensiones se han hecho evidentes desde finales de los años ochenta respecto a productos tabacaleros, para los cuales Australia, Nueva Zelanda y Canadá, entre otros, han propuesto un empaquetado genérico que restrinja las marcas.

La estandarización del envasado de ciertos productos por razones de salud pública toma auge a partir del año 2012, específicamente en la Ley de Empaquetado Genérico para el Tabaco en Australia ${ }^{1}$. El Gobierno australiano aprobó esta legislación, conocida comúnmente como de empaquetado "genérico" o "estandarizado", que prohíbe mostrar las marcas en el empaquetado del tabaco y exige que todos los productos se vendan en paquetes prácticamente idénticos, con el claro objetivo de reducir el consumo de tabaco. Sin embargo, esta ley no ha podido mostrar los resultados que se esperaba.

Actualmente son más de 20 países los que han implementado o están promoviendo iniciativas de empaquetado genérico para el tabaco, entre ellos Bélgica,

\footnotetext{
* Abogada, magíster en Gestión de la Propiedad Intelectual, Oficina Cubana de la Propiedad Industrial, y Magíster en Derecho Constitucional y Administrativo, Universidad de La Habana, Cuba. Alumna del programa de doctorado en Derecho, Universidad de Los Andes, Santiago de Chile (Chile). Contacto: mmcandano@gmail.com. Fecha de recepción: 8 de mayo de 2017. Fecha de aceptación: 26 de mayo de 2017. Para citar el artículo: Cándano-Pérez, M. "Empaquetado genérico: retos y desafíos para el derecho marcario", Revista La Propiedad Inmaterial n. ${ }^{\circ}$ 23, Universidad Externado de Colombia, enero-junio 2017, pp. 187-213. DoI: https://doi.org/10.18601/16571959.n23.08

1 Conforme a la OMC, "con colores y tipos de letra normalizados en lugar de logotipos de marcas, habitualmente, con grandes advertencias sanitarias". Ver Tobacco Plain Packaging Act, n. ${ }^{\circ}$ 148, 2011, An Act to discourage the use of tobacco products, and for related purposes. Disponible en: http://www.wipo.int/wipolex/es/text.jsp?file_id=271351
} 
Burkina Faso, Canadá, Chile, Finlandia, Francia, India, Irlanda, Hungría, Nepal, Noruega, Nueva Zelanda, Pakistán, Reino Unido, Sri Lanka, Sudáfrica, Suecia, Tailandia, Togo, Turquía y Uruguay. Todos, en mayor o menor medida, han enfrentado obstáculos normativos derivados del derecho de propiedad intelectual.

Los cuestionamientos tanto a nivel internacional como a nivel nacional se refieren a la facultad que tienen los Estados para limitar o restringir el uso de marcas comerciales, a través de la homogeneización del empaquetado del tabaco para la protección de la salud pública, lo cual vulnera los derechos de propiedad intelectual.

En el ámbito internacional, la controversia se centra principalmente en la supuesta infracción de las normas contenidas tanto en acuerdos de inversiones como en acuerdos comerciales que contienen una fuerte protección a la propiedad intelectual, a diferencia de otros tratados que reafirman el derecho de todas las personas al máximo nivel de salud posible, a partir de la implementación de medidas para reducir el consumo de tabaco. Tal es el caso del Convenio Marco para el Control del Tabaco, de la Organización Mundial de la Salud (en adelante, смст омs)².

Sin embargo, a nivel nacional las principales preocupaciones se fundan en la restricción o privación del derecho de propiedad intelectual, en este caso la marca comercial, la cual se encuentra garantizada de manera casi absoluta en algunos sistemas jurídicos, por lo que cualquier limitación o privación implica resarcir perjuicios al titular ${ }^{3}$.

En este artículo se realiza un examen de la política del empaquetado genérico introducida por Australia, a la luz del derecho a la salud y el derecho de marcas, en virtud de los tratados internacionales relacionados con la materia, teniendo en cuenta que esta normativa que se ha comenzado a aplicar en varios países del mundo lo que busca es proteger los derechos colectivos asociados a la salud pública, pero sin tener en cuenta la evidente desprotección de los derechos de los titulares de las marcas, a los que se les imposibilita utilizar sus signos distintivos tal y como se encuentran registrados, lo cual trae consigo numerosas consecuencias.

\section{LA POLÍtTICA DEL EMPAQUETADO GENÉRICO Y SU EFECTO POSITIVO EN LA DISMINUCIÓN DEL CONSUMO DE TABACO}

Una vez que se ha tenido evidencia científica sobre los efectos nocivos del consumo de tabaco, los gobiernos locales han desplegado ingentes esfuerzos para disuadir a los consumidores, mediante todo tipo de iniciativas, como campañas de concienciación o imposiciones tributarias que se reflejan en el precio de venta al público de los productos del tabaco. Lo anterior, en consonancia con el referido principio

2 Ver Organización Mundial de la Salud, Convenio Marco de la oms para el Control del Tabaco, 2003, reimpresión actualizada, 2004, 2005, (Clasificación LC/NLM: HD 9130.6). Disponible en: http://www.who.int/tobacco/framework/wHO_fctc_spanish.pdf

3 Cifuentes Castro, Andrés Felipe, "Lain packaging: controversias alrededor de las restricciones al uso de marcas registradas vinculadas a los productos del tabaco", Revista de Derecho Privado, n. ${ }^{\circ}$ 53, enero, 2015, pp. 266-290. 
de precaución, complementado con el principio de prevención ${ }^{4}$. Estas medidas, aun cuando sean polémicas, atienden a la responsabilidad que atañe a los gobiernos como garantes de un daño masivo y previsible.

Las medidas de empaquetado genérico han buscado otra manera de desincentivar el consumo de tabaco con la disociación de la evocación emocional de la marca mediante la homogeneización de colores, formas, bordes, relieve o tipografía, que son reemplazadas con imágenes disuasivas y advertencias que han ido ocupando una superficie cada vez mayor en las cajetillas.

Es una herramienta que se utiliza frente a las distintas estrategias de la industria del tabaco, y tiene diversas ventajas como, por ejemplo, hacer menos atractivo su consumo, sobre todo para mujeres y jóvenes. Desde la perspectiva del consumidor, se demuestra que la mayoría de los fumadores no son capaces de identificar su marca habitual cuando se les vendan los ojos. Según los facultativos, "esto demuestra que la marca no es más que una imagen transmitida por el envasado y la publicidad que no corresponde a una característica singular del producto"s.

Otra de las ventajas de este empaquetado es que reduce las falsas creencias de que hay cigarrillos menos peligrosos para la salud y aumenta la percepción de riesgo que supone su consumo, lo cual cuenta, según diferentes encuestas europeas, con el apoyo de la población. Por ejemplo, en Australia (país donde ya está implantada esta medida) se ha comprobado un aumento al apoyo del empaquetado neutro, incluso entre los fumadores, pasando de un $28 \%$ a un $51 \%$. El envase neutro alienta a los fumadores a dejar de fumar y/o no iniciarse en el consumo de tabaco, además de que desincentiva el contrabando ${ }^{6}$.

Según un estudio publicado en la revista Addiction $^{7}$, el envase neutro hace que los adolescentes fumadores presten más atención a las advertencias sanitarias de las cajetillas de cigarrillos. A su vez, el porcentaje de personas mayores de 14 años que fuman ha bajado en Australia del 15,1\% al 12,8\% entre 2010 y 2013. Un dato

4 Rodríguez, Gloria Amparo y PÁez-PÁez, Iván Andrés, "Las medidas preventivas ambientales, una aproximación desde el derecho administrativo”, Opinión Jurídica, vol. 23, n, ${ }^{\circ} 17$, enero-junio, 2013, pp. 17-30. Disponible en: http://revistas.udem.edu.co/ index.php/opinion/article/view/563

5 Según informe de la Universidad de Waterloo para el Gobierno de Irlanda en el año 2014 sobre la evidencia que apoya el empaquetado genérico, "los documentos internos de la industria tabacalera muestran evidencia consistente y homogénea de que el empaquetado es una herramienta promocional útil para influir en las percepciones de riesgo de los consumidores, estableciendo imágenes de marcas específicas, así como promoviendo actitudes y conductas positivas respecto al consumo de tabaco". D. Hammond, "Standardized Packaging of Tobacco Products Evidence Review”, March, 2014, Disponible en: http://health.gov.ie/blog/publications/standardised-packaging-d-hammond

6 Australia fue el primer país del mundo en implementar el empaquetado genérico, en 2012, y la evidencia científica acumulada hasta ahora demuestra que: disminuyó la prevalencia y el consumo de tabaco en 0.55 puntos porcentuales en poco más de un año, atribuible solo al empaquetado genérico, lo que implica que haya 105.000 fumadores menos en Australia desde que se instauró la medida; bajó el contrabando de cigarrillos; se produjo un ahorro para el presupuesto público de 273 millones de dólares australianos, por la reducción de costos relacionados con enfermedades causadas por el consumo de tabaco.

7 Publicada desde 1884 por la Society for the Study of Addiction, Robert West ed. Disponible en: http://www.addictionjournal.org/ 
que muestra la influencia de la implantación del envase neutro y del incremento de un 25\% en los impuestos, establecidos en 2012.

Existen otros criterios a favor del empaquetado genérico, quienes manifiestan que los actuales envases de cigarrillos son la mejor publicidad que tiene hoy la industria, lo cual no implica la eliminación de la marca y solo desaparecen las características asociadas a éstas que no son más que un vehículo de promoción y propaganda de productos del tabaco ${ }^{8}$.

En Chile, a la industria tabacalera le preocupa que sea implementado el empaquetado genérico, porque se ha demostrado que disminuye el consumo de tabaco9. En un estudio realizado a fines de 2015 en la Escuela de Salud Pública de la Universidad de Chile, en conjunto con la Organización Panamericana de la Salud $^{10}$, se demuestra que en este país los adolescentes consideran que el empaquetado genérico transmite menos la imagen de éxito, exclusividad, sociabilidad, juventud y el concepto "light", lo cual ayuda a mantenerse sin fumar más que la cajetilla actual.

En virtud de esta realidad, Chile se adscribió a las tendencias mundiales convenidas en el Tratado Marco sobre Tabaco de la oms/onu que regulan y restringen de manera estricta el uso, comercialización, publicidad y demás aspectos relacionados con el consumo de tabaco, dictando una de las primeras leyes de la región sobre el tema, la Ley 19.419 del Tabaco de 1995, reformada mediante Ley 20.105 de 2007 para ajustarla precisamente a estas tendencias y con el objeto preciso de adecuarse al tratado antes mencionado.

Esta ley, fruto de la discusión legislativa y la fuerte presión de las tabacaleras y de los sectores conservadores del parlamento, flexibilizó ciertas exigencias planteadas, tanto en el tratado como en mociones que originaron la reforma, lo que ha implicado que los indicadores sanitarios chilenos no hayan variado mayormente, circunstancia que invita a plantear una nueva enmienda a la actual legislación. Por lo anterior, se ha propuesto un nuevo proyecto de ley modificatorio de la Ley 20.105 , en la que se prohíbe totalmente la publicidad del tabaco o de elementos de la marca relacionados con dicho producto ${ }^{11}$.

8 Ver Valenzuela Sch., María Teresa, "Empaquetado genérico en productos del tabaco: éxito comprobado en disminución del tabaquismo", ponencia dictada en la Escuela de Salud Pública, Universidad de Chile, septiembre de 2016. Disponible en: http://www. chilelibredetabaco.cl/wp-content/uploads/2016/12/HojaInform-Empa-Generico-dec7.pdf

9 Se ha demostrado que el empaquetado genérico les quita a las cajetillas aquellas características que atraen a los adolescentes y que les incentivan a fumar, ya que mostrar la marca les da una imagen de persona exitosa, interesante y sociable. El proyecto de ley actualmente está en discusión en la Cámara de Diputados (Boletín n.o 8.886-11). Disponible en: www.camara.cl/pley/pley_buscador.aspx

10 Ver Erazo, M. y Bertoglia, M. P., "Percepción de riesgo en el diseño de las cajetillas de cigarrillos en adolescentes de 7 mo. básico a 4to. medio, Región Metropolitana, Chile", 2015. Disponible en: www.saludpublica.uchile.cl/noticias/121716/esp-entregaresultados-de-estudio-que-modificarian-ley-de-tabaco

11 Boletín n.o 7.456-11, del Senado, Chile. Disponible en: http://www.senado.cl/ appsenado/index.php? $\mathrm{mo}=$ sesionessala $\& \mathrm{ac}=$ getCuenta $\&$ iddocto $=40397$ 


\section{BREVE COMENTARIO A LA LEY AUSTRALIANA}

Australia es el líder mundial en la lucha contra el tabaquismo, pues se enfrenta a la industria tabacalera con una de las leyes más estrictas, a la cual se ha hecho mención y que es tenida en cuenta por muchos países en el mundo ${ }^{12}$.

La Ley de Tabaco de Australia, que comenzó a regir el 1. ${ }^{\circ}$ de diciembre de 2012, establece que las cajetillas deben ser homogéneas y estar libres de publicidad. El color verde oliva que ahora las caracteriza va acompañado de imágenes ilustrativas de los riesgos que representa el tabaquismo para la salud. El nombre de la marca solo puede aparecer en pequeñas letras, mientras que las advertencias ocupan el $75 \%$ de la parte frontal y el $90 \%$ de la parte posterior de los envoltorios, como una forma de obstaculizar el mercadeo de la industria del tabaco.
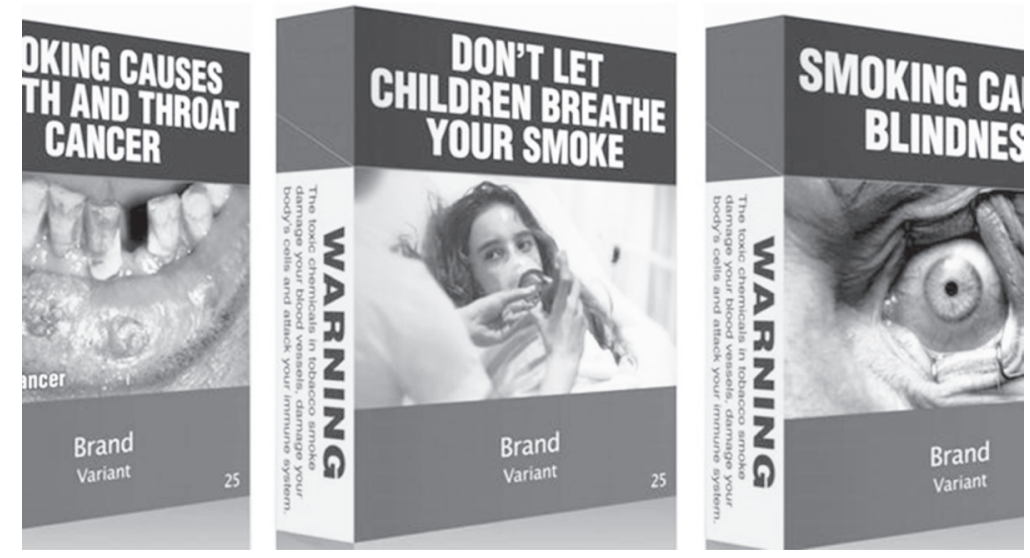

A nivel interno, la Asociación Australiana de Minoristas teme que el carácter intervencionista de la administración pública derive en una peligrosa espiral de prohibiciones que podría incluir el consumo de alcohol y alimentos ricos en grasa. Sin embargo, y a través del Acuerdo Nacional de Salud actualizado en 2012, el Gobierno australiano aclara que su objetivo principal es reducir la cifra de fumadores de un 15\% actual a un 10\% para el año 2018.

Las bases de estas restricciones son estudios -como el elaborado por la organización Cáncer Council Australia- cuyo resultado evidencia que el empaquetado genérico de los productos de tabaco disminuye su atractivo para los consumidores -también para los jóvenes y potenciales fumadores-, a la vez que incrementa la efectividad de las advertencias de salud y reduce la posibilidad de que los consumidores piensen que existen cigarrillos menos nocivos que otros.

12 Entre ellos Chile, cuya nueva Ley de Tabaco fue aprobada el 3 de enero 2013 por la Cámara de Diputados. Ver Ley 20.660, de 1 de marzo de 2013, del Ministerio de Salud, Subsecretaría de Salud Pública, que modifica la Ley n. ${ }^{0} 19.419$, en materia de ambientes libres de humo de tabaco. Disponible en: http://www.leychile.cl/Navegar?idNorma=1047848 


\section{El CASo inglés. Una REFERENCIA NECESARIA}

El Tribunal Supremo del Reino Unido se ha pronunciado con una sentencia sobre la demanda que hiciera la industria tabacalera con ocasión de la adopción del reglamento sobre el empaquetado sencillo de tabaco ${ }^{13}$. En el fallo se rechazan todos los argumentos del recurso de la industria tabacalera, y se decide que el empaquetado genérico no viola los derechos de propiedad intelectual de las empresas tabacaleras, por cuanto las restricciones impuestas buscan defender el legítimo interés de la salud pública. Así, las empresas tabacaleras no tienen derecho a una indemnización, pues la epidemia de salud que perpetúa la industria crea unos enormes costos de salud sobre el propio Estado del que la industria espera ser compensada por sus "pérdidas" de propiedad.

Por lo tanto, desde el 20 de mayo de 2016 todos los productos de tabaco fabricados para su comercialización en el Reino Unido deben cumplir con la nueva legislación y solo se venderán en un envase marrón verdoso.

El Tribunal Superior del Reino Unido también ha rechazado el argumento de la industria tabacalera de que el reglamento es desproporcionado, y la sentencia lo ha calificado como "adecuado y apropiado" por numerosas razones. Más aún, el Tribunal ha declarado que el reglamento trata de salvar a los niños de una "vida de adicción, y a los niños y adultos de una muerte prematura y del sufrimiento y las enfermedades relacionadas con el tabaco". El razonamiento central del juez sobre la aplicación del Convenio Marco para el Control del Tabaco de la oms demuestra la importancia del Convenio y confirma la alta consideración de que goza en el marco de la normativa británica.

Por otra parte, el tribunal británico ha llegado a la conclusión de que es conveniente que el Gobierno responda a las consultas de la industria tabacalera con suma precaución, habida cuenta del conocido historial de la industria de falta total de referencia a la documentación o datos nacionales, así como de su incumplimiento de las buenas prácticas reconocidas a nivel internacional.

Esta histórica sentencia del Tribunal Superior del Reino Unido confirma que el смСт, en cuanto tratado basado en pruebas científicas, es un elemento decisivo en los procesos judiciales, y que los gobiernos han de utilizar sus disposiciones y

13 Tribunal de Justicia (Sala Segunda). Sentencia de 4 de mayo de 2016. Asunto: C-547/14. Partes: Philip Morris Brands SARL et al. v. Secretary of State for Health. Petición de decisión prejudicial planteada por High Court of Justice Queen's Bench Division (Administrative Court). Procedimiento prejudicial - Aproximación de las legislaciones - Directiva 2014/40/UE - Artículos 7, 18 y 24, apartados 2 y 3 - Artículos 8, apartado 3, 9, apartado 3, 10, apartado 1, letras a), c) y g), 13 y 14 - Fabricación, presentación y venta de los productos del tabaco - Validez - Base jurídica - Artículo 114 TFUE - Principio de proporcionalidad - Principio de subsidiariedad - Derechos Fundamentales de la Unión - Libertad de expresión - Carta de los Derechos Fundamentales de la Unión Europea - Artículo 11. Disponible en: http://eur-lex.europa.eu/legal-content/ ES/TXT/?uri=CELEX:62014CJ0547 
directrices en los litigios para defender la salud pública frente a los intereses de la industria tabacalera.

En este sentido, la High Court of Justice of England and Wales ha rechazado los argumentos de las tabacaleras basándose en la evidencia del impacto del empaquetado genérico en el consumo de tabaco, en la necesidad de complementar las estrategias individuales de control del tabaquismo con medidas más amplias, en virtud de los objetivos de salud pública frente al derecho de propiedad y de marca en el Reino Unido, y por último en la necesidad de dar cabal cumplimiento al Convenio Marco.

\section{IMPACTO NEGATIVO DEL EMPAQUETADO GENÉRICO}

PARA LOS TITULARES MARCARIOS

Desde los inicios de la década de los ochenta, el empaquetado genérico de tabaco fue una de las iniciativas preventivas dirigidas a distorsionar no solo la marca, sino cualquier cualidad evocativa en las cajetillas de cigarrillos. De hecho, la primera propuesta implicaba que el producto en cuestión se comercializara en papel de manila en el territorio canadiense ${ }^{14}$, país en cuyo Parlamento, en la década siguiente, fue radicado sin ningún éxito un proyecto de ley que pretendía regular el empaquetado genérico en la industria tabacalera.

La razón para que tanto este como otros proyectos normativos fracasasen en su momento ${ }^{15}$ fue la férrea oposición de esta influyente industria, que invocaba la preocupante afectación que la medida representaba para las marcas, su principal activo intangible, y para otros derechos de propiedad intelectual, entre los que destacaba el derecho de autor sobre las ilustraciones, los diseños industriales y los modelos de utilidad de las cajetillas, el goodwill del producto y los derechos de empaquetado ${ }^{16}$, que comprenden desde la manufactura, venta, utilización e importación de los empaques hasta el diseño que el titular de una marca decida utilizar para promocionar su producto.

Por tal motivo estimo que existen argumentos que evidencian claramente el impacto negativo que tiene esta medida de empaquetado genérico para los derechos de los titulares marcarios.

14 Lou Lee, Betty, "Sell Tobacco in No-frills Wrappers, Urge Doctors", 15 The Journal of the Addiction Research Foundation, año 15, n. ${ }^{\circ} 10,1$ de octubre de 1986, pp. 1-5.

15 Tenorio, Luis Felipe, "Cigarrillos y malteada de chocolate: la Tobacco Plain Packaging Act australiana de 2011", Criterio Jurídico, año 12, n.o 2, diciembre, 2012, pp. 151-180. Disponible en: http://revistas.javerianacali.edu.co/index.php/criteriojuridico/ article/download/624/823

16 Al respecto, Williams, Stephen, "The More Law, the Less Rule of Law", The Green Bag an Entertaining Journal of Law, año 2, n. ${ }^{\circ} 4$, 1999, pp. 403-409. Disponible en: http://www.greenbag.org/v2n4/v2n4_articles_williams.pdf Liberman, JonATHAN, "Plainly Constitutional: The Upholding of Plain Tobacco Packaging by the High Court of Australia", American Journal of Law \& Medicine, 39, 2013, pp. 361-381. Disponible en: http://papers.ssrn.com/sol3/papers.cfm?abstract_id=2215346 


\section{I. Afectación a la función de la marCa}

La doctrina es uniforme en cuanto a que la función fundamental de las marcas radica en su distintividad, y las demás funciones simplemente se derivan de tal capacidad o se someten a esta. Así, para Otamendi, "la verdadera y única función esencial de la marca es distinguir un producto o un servicios de otros" ${ }^{17}$.

La distintividad irradia sus efectos más allá de la obtención del registro y debe persistir durante toda la vida de la marca como requisito de conservación del registro, en otras palabras, si se pierde lo distintivo del signo pueden verse en peligro los derechos otorgados al titular de la marca a partir del registro otorgado en su momento.

En tal sentido, se causa un grave perjuicio a los derechos del titular de la marca, por perder todos aquellos atributos evocativos y diferenciadores de la misma, lo que habría que precisar si efectivamente estas medidas de empaquetado genérico logran moderar el consumo de tabaco, por lo que esa sería la primera interrogante. Algunos estudios ${ }^{18}$ han evidenciado que estas medidas no mitigan el consumo; y aunque lograran moderarlo, la industria puede optar por un sistema de precios bajos, que promueva el consumo en grupos poblacionales con un escaso poder adquisitivo, como el de los jóvenes.

\subsection{Afectación al uso}

En cuanto al derecho a la marca se aprecia que, una vez que se lleva a cabo el registro, se tiene en esencia un derecho positivo al uso y un derecho negativo a impedir que otro use, pero en este caso con las medidas de empaquetado genérico se obstaculiza el carácter de la marca, se afecta el modo de usarla, y además, con la prohibición de usar los signos distintivos, tal y como se encuentran registrados, en todos los envases de venta minorista del tabaco, incluso cuando se vende por unidades, se anulan totalmente las funciones de una marca, en particular la capacidad de asociar el producto a un origen, a un productor y a una tradición. Ni siquiera es posible hacer uso del sello de garantía que identifica y asegura la autenticidad del origen ${ }^{19}$.

17 Otamendi, Jorge, Derecho de marcas, 7.a ed., Buenos Aires, Abeledo-Perrot, 2010, p. 470 .

18 Entre otros, Browne, Jaron; Hennessey-Lavery, Susana y Rogers, Kim, "Valen más que mil palabras, las etiquetas de advertencias pictóricas de tabaco y los derechos lingüísticos de Estados Unidos", Power, Tobacco Free Coalition, Data Center, 3-20, 6, Reports on Industry Activity from Outside, University of California, San Francisco, Center for Tobacco Control Research and Education (2007). Disponible en: https://escholarship.org/uc/item/1db2x4wn Culliton-González, Katherine, "The Impact of Alcohol and Tobacco Advertising on the Latino Community as a Civil Rights Issue", 16 Berkeley La Raza Law Journal (2005). Disponible en: http://works.bepress.com/katherine_culliton/2/ Husten C., K. Jackson y LeE, C., "Cigarette smoking among adults - United States 2002", Morbidity and Mortality, Weekly Report, 53, 20, 8 de mayo, 2004, p. 427 Disponible en: http://www.ncbi.nlm.nih. gov/pubmed/15163928 - http://www.cdc.gov/mmwr/preview/mmwrhtml/mm5320a2.htm

19 Esto es de especial relevancia para el tabaco cubano que es elaborado artesanalmente, a mano y en un $100 \%$ natural. 
El uso se demuestra entonces, con la venta de productos o la prestación de servicios bajo la correspondiente marca, lo cual quiere decir que debe existir una conexión material o corporal entre la marca registrada y el producto o envoltorio.

Es oportuno aclarar que el titular de la marca tiene, como contrapartida al derecho de exclusiva que se le concede con su registro, la carga de usarla. El principio del uso obligatorio de la marca registrada es esencial, y se satisface mediante el empleo de modo efectivo y rea ${ }^{20}$ de aquellos productos o servicios para los que se registró, como se aprecia en la legislación cubana ${ }^{21}$.

En este sentido se evidencia que si lo que está registrado como marca no se puede usar, esto trae consigo numerosas consecuencias. Ejemplo de ello es la caducidad por falta de uso, que tiene lugar cuando la marca no sea objeto de un uso real y efectivo dentro del territorio nacional para distinguir los productos o servicios para los cuales haya sido concedida, por el titular o por un tercero con su consentimiento, o si dicho uso se hubiese suspendido de forma ininterrumpida por el mismo período.

\subsection{Falsificación y tráfico ilí́cito de productos de tabaco}

Si con estas medidas se afecta en esencia el modo de usar la marca, traen consigo también otras consecuencias como la falsificación y el tráfico ilícito de productos de tabaco, siendo copiados los objetos protegibles en propiedad intelectual, desde una cajetilla plana sin distintivos holográficos, hasta los mecanismos de seguridad visual o de relieve, que se prohíben por las medidas de empaquetado genérico.

\subsection{Desproporcionalidad entre normas}

Es pertinente abordar las incompatibilidades de las medidas de empaquetado genérico con el régimen vigente de propiedad intelectual y la desproporcionalidad de estas medidas, por medio de una línea argumentativa que busca reafirmar la marca de tabaco como un signo distintivo que, con todos sus atributos y ejes caracterizadores, merece un igual trato en comparación con otras marcas y, por tanto, una legítima protección por parte de los Estados.

Hoy, cuando los sistemas jurídicos se replantean frente a compromisos internacionales de naturaleza económica, comerciales o de inversiones, es necesario

20 Entiéndase uso real y efectivo: "cuando, en consonancia con su función esencial, que consiste en garantizar la identidad del origen de los productos o servicios para los que haya sido registrada, se utiliza con el fin de crear o conservar un mercado para tales productos y servicios, excluyéndose usos de carácter simbólico cuyo único objeto sea el mantenimiento de los derechos conferidos por la marca": Juzgado de lo Mercantil n. ${ }^{\circ} 8$, Madrid. Sentencia 84/2015, Recurso de apelación 260/13. Disponible en: http://www. poderjudicial.es/search/doAction? action $=$ contentpdf\&databasematch $=$ AN \& reference $=735$ 4584\&links $=$ \&optimize $=20150422 \&$ publicinterface $=$ true

21 República de Cuba. Decreto-Ley 203, de marcas y otros signos distintivos, de 24 de diciembre de 1999, Gaceta Oficial Extraordinaria n.o 31, 2000. 
perfilar flexibilidades reales y concretas - más allá de declaraciones de intenciones incorporadas en la mayoría de los acuerdos-, que resguarden intereses superiores justificados. De igual manera, a nivel interno se requiere delinear los derechos de propiedad intelectual más allá de las limitaciones existentes ${ }^{22}$, ya que estas no han sido aptas para enfrentar los desafíos que actualmente plantea la salud pública.

En fin, como bien se ha dicho, las marcas destacan y diferencian unos productos de otros en el mercado y a su vez transmiten la alta calidad. El empaquetado genérico priva a los consumidores de esta información y los trata como si no pudieran tomar sus propias decisiones, reduce el atractivo, elimina la posibilidad de introducir elementos distintivos y de utilizar el empaquetado como vehículo promocional, a la vez que priva a los titulares de las numerosas inversiones que han llevado a cabo para desarrollar esas marcas, además de despojar a las marcas de su objetivo, pues exige que todos los productos tengan el mismo aspecto en el mercado, sin atender a la calidad u otras características.

\section{El acuerdo sobre los aspectos de los derechos de propiedad INTELECTUAL RELACIONADOS CON EL COMERCIO Y SU INCOMPATIBILIDAD CON LA POLÍ́TICA DE EMPAQUETADO GENÉRICO}

Una vez incorporado el empaquetado genérico a los productos de tabaco, han tenido lugar intensos debates en numerosos escenarios, como la OMC, por medio de su organismo de solución de controversias. Así, varios países han iniciado ante la OMC reclamaciones contra la Tobacco Plain Packaging Act australiana. Esta ha sido objeto de cinco impugnaciones jurídicas, a saber, las diferencias DS434 (planteada por Ucrania), DS435 (planteada por Honduras), DS441 (planteada por la República Dominicana), DS458 (planteada por Cuba) y DS467 (planteada por Indonesia) ${ }^{23}$.

Todos los países manifiestan su apoyo a los objetivos que se persiguen en materia de salud, pero reiteran su preocupación por la posibilidad de que se infrinja el Acuerdo sobre los Aspectos de los Derechos de Propiedad Intelectual relacionados con el Comercio (ADPIC), al impedir que los productores de tabaco usen sus marcas

22 Agotamiento del derecho, licencias obligatorias, excepción Bolar, entre otras.

23 Otros documentos de reclamación son: G/твт/w/365 (Cuba), G/твт/w/366 (República Dominicana), G/твт/w/368 (Malawi), wт/DS434, wт/Ds435 у wT/Ds441 (República Dominicana). омс (wто), Comité de Obstáculos Técnicos al Comercio 17, Intervención de Cuba, 19-20 de junio de 2013, G/твт/w/365 (Cuba). Disponible en: https://docs. wto.org/dol2fe/Pages/FE_Search/

- DDFDocuments/117700/q/G/твт/w365.pdf - http://www.puntofocal.gov.ar/doc/w365. pdf омс (wто), Comité de Obstáculos Técnicos al Comercio 17, Intervención de República Dominicana, 19-20 de junio de 2013, G/твт/w/366. Disponible en: http://www. smoke-free.ca/trade-and-tobacco/Ireland/W366.pdf - http://www.puntofocal.gov.ar/doc/ w366.pdf омс (wто), Comité de Obstáculos Técnicos al Comercio 17, Intervención de Malawi, 19-20 de junio de 2013, G/твт/w/368. Disponible en: http://www.smoke-free. ca/trade-and-tobacco/Ireland/W368.pdf омC (wто), wт/Ds434, wT/Ds435 у wT/Ds441 (República Dominicana). Disponible en: http://dfat.gov.au/international-relations/international-organisations/wto/wto-dispute-settlement/Documents/procedural-agreement.pdf 
de comercio e indicaciones geográficas para distinguir tales artículos, lo cual crea obstáculos innecesarios al comercio, ofrece a los productos importados un trato menos favorable y vulnera los derechos de propiedad intelectual.

Para un adecuado análisis de estas reclamaciones, a continuación trata de manera separada cada una de las argumentaciones presentadas al efecto por los distintos países.

\section{I. INCOMPATIBILIDAD DEL EMPAQUETADO GENÉRICO AL REGISTRO DE MARCAS RESPECTO A CUALQUIER PRODUCTO}

De acuerdo al artículo 15.4 del ADPIC, "La naturaleza del producto o servicio al que la marca de fábrica o de comercio ha de aplicarse no será en ningún caso obstáculo para el registro de la marca". De esta manera, se sostiene por los países reclamantes que el empaquetado genérico sería contrario a la disposición citada, en atención a que estas medidas tienen que ver con la naturaleza del producto asociado a la marca, pues se convierte en un obstáculo para su registro. Sobre este punto, el ADPIC señala que la naturaleza del producto no puede ser impedimento para su registro de marca. De este modo, claramente el empaquetado genérico contraviene dicha disposición.

De igual forma se incumple lo dispuesto en el artículo 15.1 sobre la materia objeto de protección, norma que establece que "podrá constituir una marca de fábrica o de comercio cualquier signo o combinación de signos que sean capaces de distinguir los bienes o servicios de una empresa de los de otras empresas", siendo claro que se trata de la distintividad marcaria en este sentido ${ }^{24}$.

Este argumento ha sido expuesto por Cuba y por la República Dominicana en su reclamo, planteando que a partir de estas medidas ni siquiera es posible hacer uso del sello de garantía que identifica y asegura la autenticidad del origen, por lo que la aplicación de la ley a un producto con tales características impide la asociación de las marcas a estos rasgos distintivos y por lo tanto anula su valor comercial en ese territorio, al tiempo que limita el derecho de los consumidores a decidir por la calidad de un producto asociada a su marca ${ }^{25}$.

Contra esto Australia, al notificar su iniciativa ante la oMC, manifiesta que el tabaco debe tratarse como una sustancia peligrosa, y no como un producto ordinario. La medida busca hacer las advertencias de salud y la información más visibles. Esta posición se funda en investigaciones científicas que señalan que "las advertencias sobre empaquetados genéricos pueden ser más efectivas captando la atención e incrementando el recuerdo del mensaje en comparación con los empa-

24 Ver Acuerdos sobre los Derechos de Propiedad Intelectual relacionados con el Comercio (ADPIC), adoptados en la Ronda de Uruguay del GATT, 1994, art. 15.

25 омс (wто). Disponible en: https://www.wto.org/spanish/tratop_s/dispu_s/dispu_current_status_s.htm 
quetados regulares, y que las políticas de salud pública tienen prioridad sobre los derechos de las corporaciones" ${ }^{\prime 26}$.

A su vez, se explica que el objetivo es "modificar el aspecto de los productos de tabaco de forma que resulten menos atractivos para los consumidores" y "reducir la posibilidad de que los envases de productos de tabaco induzcan a error a los consumidores acerca de sus efectos perjudiciales" ${ }^{27}$.

\subsection{El empaQuetado genérico No SE ENCASIlla DeNTRo Del CONCEPTO DE EXCEPCIÓN LIMITADA A LOS DERECHOS DE PROPIEDAD INTELECTUAL}

El artículo 17 del ADPIC permite a los Estados parte establecer excepciones a los derechos marcarios, pero ello solo puede tener lugar si se atiende a los intereses legítimos del titular de la marca y de terceros.

Cuba, Ucrania y Puerto Rico han planteado que no es posible considerar el envasado genérico como una excepción "limitada", ya que prohíbe totalmente la utilización de determinados símbolos e impone estrictas exigencias para otros, sin intentar siquiera tener en consideración los derechos del titular de la marca ${ }^{28}$.

La expresión "excepciones limitadas" se refiere solamente a una pequeña disminución de los derechos. "El hecho de que sólo pueda afectar a pocas marcas de fábrica o de comercio o sus titulares no es pertinente a la cuestión de si una excepción es limitada". "Lo que hay que decidir es si la excepción de los derechos conferidos por una marca de fábrica o de comercio es restringida" ${ }^{29}$. Esto, debido a que el empaquetado genérico implica la cuasi-anulación de las marcas, luego resulta difícil encuadrarlo como la "excepción limitada" al derecho de marcas que prevé el artículo 17 del ADPIC.

\subsection{El empaquetado genérico impide el uso legítimo DE LA MARCA COMERCIAL}

Con el empaquetado genérico se establecen medidas que impiden el libre uso de la marca, como "el uso de una forma especial, por ejemplo, el tipo y tamaño de letra y ubicación del nombre de marca, y el uso de una presentación que menoscaba la capacidad de la marca para distinguir los productos de tabaco de una empresa de los de otras empresas" ${ }^{\prime 30}$; por tanto, se incumple el artículo 20 del ADPIC, el cual

26 Organización Mundial de la Salud, Debates sobre salud, empaquetado de productos del tabaco y observancia en el Consejo de los ADpic, celebrado el 24 y 25 de octubre de 2011. Disponible en: https://www.wto.org/spanish/news_s/news11_s/trip_24oct11_s.htm 27 Ibíd.

28 омс (што). Proyecto de Ley relativa al envasado genérico del tabaco de 2011, notificado por Australia, IP/C/w/567, de 14 de diciembre.

29 Gil Albinader, Luis, "El empaquetado genérico de cigarrillos y la propiedad intelectual”, Puentes, vol. 12, n.o 4, ICTSD, 3 de noviembre de 2011.

30 омс (wто). Solución de Controversias DS441: determinadas medidas relativas a las marcas de fábrica o de comercio, indicaciones geográficas y otras prescripciones de 
señala que no se complicará injustificadamente el uso de una marca de fábrica o de comercio en el curso de operaciones comerciales con exigencias especiales.

Los países reclamantes afirman que como el empaquetado genérico impide que la marca pueda desplegarse dentro de la estrategia publicitaria del empresario tabacalero, entonces se obstaculiza el goce de los derechos que como titular le fueron conferidos previamente con el registro.

Además, no hay garantías de protección de los derechos de los titulares, con lo cual se incumple lo preceptuado en el artículo 16 del ADPIC, que establece las potestades de goce que tienen los titulares, y el ius prohibendi respecto a terceros que hagan uso de signos idénticos o similares a los propios.

Sin embargo, Australia presenta una interpretación diferente, al indicar que la prohibición del derecho de uso de marcas figurativas, frases de propaganda y restricciones a las marcas denominativas no vulnerarían ningún derecho contemplado en el ADPIC, ya que considera que el derecho conferido por el registro solo habilita a su titular para impedir utilizaciones no consentidas, pero no a usar, lo que se llama faz positiva del derecho marcario.

\subsection{El empaquetado genérico facilita la ocurrencia DE ACTOS DE COMPETENCIA DESLEAL}

Es necesario reiterar otro aspecto importante, y es que con las medidas de empaquetado se impide el uso eficaz de la marca, por lo que no se logra una distinción de los productos en el mercado, lo que induce a error a los consumidores y afecta la función esencial de este signo, que es la de garantizar el origen de los productos o servicios. En este sentido, se dificulta la libre elección de estos, lo cual hace que se quiebre su voluntad mediante engaños o maniobras tendientes a confundir o inducir al consumidor a tomar decisiones económicas erradas ${ }^{31}$, en circunstancias de falsificación y competencia desleal.

Es indiscutible que la práctica de actos de falsificación de marcas y de competencia desleal genera numerosos daños al titular del registro y a la propia marca, a menudo causando perjuicios que van más allá de la reducción del consumo del producto o servicio legítimo por el mercado. Así, estas prácticas pueden conducir a daños como la desvalorización de la marca en el mundo empresarial y de los consumidores.

En tal sentido, otro de los artículos que vulnera del ADPIC es el número 22, en su párrafo 2 b), el cual remite a lo regulado en el Convenio de París: "cualquier otra utilización que constituya un acto de competencia desleal, en el sentido del 
artículo 10 bis del Convenio de París (1967)"32. En el caso de Australia, se evidencia una clara infracción de este artículo, puesto que sus autoridades no logran proporcionar una protección efectiva a los titulares de la industria tabacalera, contra todo acto de competencia desleal que se pudiese presentar sobre las indicaciones geográficas, las cuales en este país han sufrido, además, una significativa reducción de su nivel de protección, en comparación con los niveles que había antes del $1 .^{\circ}$ de enero de $1995^{[33]}$.

Cuba, por su parte, en su reclamo manifiesta la preocupación por el incremento del comercio ilícito de los productos del tabaco, por cuanto será mucho más fácil falsificar el empaque sin el uso distintivo de la marca. Por tanto, la medida que se propone para contrarrestar la falsificación de los productos es a través de un código alfanumérico único, pero tal código puede también ser reproducido en un empaque falso, y además no es evidente el efecto real que pueda tener sobre el consumidor, al cual le seguirá siendo imposible identificar si realmente está consumiendo un producto falso o no.

Honduras, a su turno, estima, que esas normas incentivan el descenso de los precios, pero también la imitación y el contrabando, además de dificultar la diferenciación de marcas de calidad, y ello sin garantizar que se asegure a los titulares de las marcas su protección ante falsificaciones o competencia desleal.

Sin embargo, Australia explicó en la reunión del Consejo de la OMC encargado de cuestiones de Propiedad Intelectual (Consejo de los ADPIC), celebrada el 7 de junio de 2011, que "la razón por la que había propuesto la ley era proseguir su campaña contra una práctica que constituía un peligro importante y mortal para la salud". Indicando que el establecimiento de impuestos especiales al consumo más elevado y la posibilidad de usar un etiquetado que evitara la falsificación encarecería los cigarrillos e impediría el contrabando. De igual forma, añade que todas esas medidas serían conformes con sus obligaciones internacionales ${ }^{34}$.

A su vez, Nueva Zelanda, Uruguay y Noruega opinan que ley de Australia está justificada, e India señala, sin referirse específicamente a dicha ley, que según varios estudios los envases genéricos reducen efectivamente el tabaquismo.

\subsection{A modo de Resumen de esta controversia}

Los Estados reclamantes han impugnado la normativa del empaquetado por considerar que Australia está incumpliendo sus obligaciones derivadas de los tratados de comercio internacional suscritos, advirtiendo del impacto económico negativo

32 Ver Convenio de París para la Protección de la Propiedad Industrial del 20 de marzo de 1883, artículo 10 bis.

33 омс (wто). Solución de Controversias DS441: determinadas medidas relativas a las marcas de fábrica o de comercio, indicaciones geográficas y otras prescripciones de empaquetado genérico aplicables a los productos de tabaco y al empaquetado de esos productos. Disponible en: https://www.wto

34 Disponible en: https://www.wto.org/spanish/news_s/news11_s/trip_07jun11_s.htm 
que ha tenido lugar en los países productores de tabaco, a partir de medidas como el empaquetamiento genérico.

Afirman además que en ninguno de los países en los que se ha adoptado este modelo se tienen evidencias de su eficacia, ya que el impacto de estas medidas es estadísticamente irrelevante, consiguiendo solo vulnerar derechos básicos en el ámbito empresarial y comercial, lo cual supone un ataque injustificado a las marcas $\mathrm{y} \mathrm{da}$ a los productos importados un trato menos favorable ${ }^{35}$.

Por su parte, Cuba y República Dominicana argumentan que esas normas afectan a sus industrias tabacaleras, consideradas de alta calidad y elevada aceptación internacional, lo cual les impedirá diferenciar sus respectivas ofertas del resto de la competencia y frenará esa importante fuente de ingresos, por lo que actúa desfavorablemente sobre sus frágiles economías.

Lo recurrente en estas reclamaciones ante la OMC ha sido la preocupación por la pérdida de la fuerza del signo distintivo en el mercado y la no utilización de este según su propósito, ya que terceros podrían aprovechar esta situación para trasladar al consumidor información sobre la procedencia del tabaco que podría causar confusión y dar lugar a conductas desleales; adicionalmente, la marca queda relegada al limitar su representación gráfica y sus factores de perceptibilidad, con lo cual consecuentemente pierde toda distintividad ${ }^{36}$.

Australia, defiende su ley y destaca los efectos nocivos que trae aparejado el consumo de tabaco, catalogándolo como una epidemia mundial de consecuencias letales. Rechaza que la práctica aplicada a los envases de cigarro y tabaco sea desproporcionada, al tiempo que defiende el carácter neutral y no discriminatorio del empaquetado genérico por aplicarse sin distinción de tipo y origen del producto, así como se estima que en ningún caso se vulnera la Constitución.

Estas argumentaciones han sido observadas de cerca por otros gobiernos de todo el mundo, como los de Noruega, Reino Unido, Nueva Zelanda, Francia, Sudáfrica, Chile y China, además de la Unión Europea, que afirman que "las tabaqueras deberían dejar de intentar bloquear la reforma a nivel internacional y seguir adelante con la aplicación de este importante cambio".

Otros países, como España, México, Uruguay, han tomado medidas similares respecto a las advertencias sanitarias en el empaquetado de cigarrillos, pero sin imponer un empaquetado genérico, permitiendo que cada empresa tabacalera utilice el logotipo que identifique a sus marcas.

35 Probablemente, el reclamo más generalizado desde varios sectores se presenta por el trato menos favorable recibido por las industrias tabacaleras de los Estados miembros, en comparación con el trato otorgado a la industria tabacalera del Estado que aplica las medidas. Ello ha llevado, en más de una ocasión, a la invocación del inciso primero del artículo 3 del ADpic, del inciso cuarto del artículo 3 del Acuerdo General sobre Aranceles Aduaneros y Comercio (GATT) y del artículo 2 del Acuerdo sobre Obstáculos Técnicos al Comercio.

36 Martínez-Salcedo, Juan Carlos y Vargas-Chaves, Iván, "La afectación de la marca de tabaco por las medidas de empaquetado genérico", Vniversitas, 130, 2015, Bogotá, p. 242. Disponible en: http://dx.doi.org/10.11144/Javeriana.vj130.amtm 
A partir de este análisis se considera que la persecución de los objetivos de salud pública y la protección de los intereses económicos pueden coexistir, pero a condición de que se tracen políticas de control del tabaco acertadas.

Los hechos demuestran claramente que el experimento del empaquetado genérico no ha reducido el consumo de tabaco en Australia, sino que ha llevado a los fumadores a pasar de productos de tabaco de primera calidad a productos más baratos lícitos e ilícitos. Por lo que hasta la fecha no se han encontrado evidencias de su eficacia, siendo el impacto de estas medidas estadísticamente irrelevante.

\section{Derecho a la SALUd Versus Derecho de marcas}

El derecho a la salud es definido por la oms como el "completo bienestar físico, mental y social" ${ }^{37}$, introducido en la Constitución de los diferentes países y reconocidos como un "derecho social" o "de segunda generación".

Los derechos humanos reconocen libertades políticas y civiles frente a las intromisiones de poder, garantizando la libertad negativa o la no interferencia del Estado en la esfera privada de los individuos. Es un derecho inseparable del derecho a la vida y se encuentra reconocido en varios instrumentos internacionales, a saber: la Declaración Universal de Derechos Humanos (art. 25.1 ${ }^{[38]}$ ), el Pacto Internacional de Derechos Económicos, Sociales y Culturales (art. 12), la Declaración Americana de los Derechos y Deberes del Hombre, la Convención sobre los Derechos del Niño (art. 24 ${ }^{[39]}$ ) y la Carta de los Derechos Fundamentales de la Unión Europea (art. 35).

Todos estos instrumentos coinciden en la necesidad de proteger la salud, así como el derecho de toda persona a la prevención sanitaria y a beneficiarse de la

37 La Constitución de la oms, de 1946, estatuye que "la salud es un estado de completo bienestar físico, mental y social, y no solamente la ausencia de afecciones o enfermedades. El goce del grado máximo de salud que se pueda lograr es uno de los derechos fundamentales de todo ser humano sin distinción de raza, religión, ideología política o condición económica o social. La salud de todos los pueblos es una condición fundamental para lograr la paz y la seguridad, y depende de la más amplia cooperación de las personas y de los Estados". Ver Smith, Intellectual Property Rights and the Right to Health, cit., p. 50. Sснотz, Gustavo J. et al., Patentes y medicinas esenciales. La armonización entre el derecho a la salud y la propiedad intelectual, Buenos Aires, Heliasta, pp. 101 ss.

38 Declaración Universal de los Derechos Humanos, art. 25, párr. 1: "Toda persona tiene derecho a un nivel de vida adecuado que le asegure, así como a su familia, la salud y en especial, la alimentación, el vestido, la vivienda, la asistencia médica y los servicios sociales necesarios".

39 Se hace mención además en la Carta Africana de Derechos Humanos y de los Pueblos (art. 16) y en el Protocolo Adicional a la Convención Americana de Derechos Humanos en el Ámbito de los Derechos Económicos, Sociales y Culturales, conocido como "Protocolo de San Salvador" (art. 10). Ver Hunt, PAul, "The right to everyone to the enjoyment of the highest attainable standard of physical and mental health", United Nations, Economic and Social Council, Commission on Human Rights, Report of the Special Rapporteur, Paul Hunt, Submitted in accordance with Commission Resolution 2002/31, E/CN. 4/2003/58, 13/02/2003, n.o 15 y 20. 
atención a la salud en las condiciones establecidas en las legislaciones y prácticas nacionales, si bien el principal problema que plantea el derecho a la salud en cuanto derecho fundamental es su interacción con otros derechos, con las dificultades de definir sus contornos y contenido e identificar las "buenas prácticas" para hacerlos operativos en los niveles local e internacional ${ }^{40}$.

Entre los temas más debatidos en materia de salud en los ADPIC, figuran las posibles contradicciones que se han observado en el artículo 8, pues por un lado se permite a los países adoptar las medidas necesarias para proteger la salud pública, mientras por otro se trata de impedir los abusos de los derechos de propiedad intelectual $^{41}$.

Un segundo requisito del artículo 8(1) es verificar que existan otros medios para lograr los objetivos de política pública perseguidos. Si bien el empaquetado genérico puede implementarse con un costo mínimo para el gobierno, también se pueden adoptar otras medidas para obtener resultados similares o equivalentes. Estas son, por ejemplo, las campañas educativas y restricciones publicitarias, que además tienen un efecto menos restrictivo sobre los derechos de propiedad intelectual ${ }^{12}$.

\section{I. Controversia A Nivel INTERnaCional}

Si se analiza la legislación interna de diversos países respecto al contenido del derecho de marca, en relación a si es derecho de exclusión o de uso, las dudas se disipan. Las normativas relativas a estándares de protección de las marcas son claras en consagrar el derecho positivo de uso de las mismas y no solo el derecho de exclusión.

Se pueden mencionar, a modo de ejemplo: la sección 1115 del Lanham Act de Estados Unidos; el artículo 25, sección 1, capítulo iv de la Ley de Marcas de Japón; la sección 15 de la Ley de Protección de Marcas e Indicaciones de Origen de Alemania; y, para el caso latinoamericano, el artículo 14 de la Ley de Marcas de Argentina, el artículo 29 de la Ley de Propiedad Industrial de Brasil, el artículo 19 bis D de la Ley de Propiedad Industrial de Chile o el artículo 162 de la Ley de Propiedad Intelectual de Perú.

Por consiguiente, el empaquetado genérico privaría o limitaría, según el tipo de medida, el derecho sobre la marca comercial determinada. Por otra parte, diversas constituciones o declaraciones de derechos contienen garantías al derecho

40 Sснотz et al., ob. cit., pp. 101 ss.

41 Cándano Pérez, Mabel, "Protección constitucional de los derechos intelectuales. Especial referencia a Cuba”, tesis presentada para optar al grado de máster en Gestión de la Propiedad Industrial, ocpi, Cuba, pp. 41 y 42.

42 Ver Borland, R.; Wilson, N.; Fong, G. T. et al., "Impact of graphic and text warnings on cigarette packs: Findings from four Countries over five years" (trad. del autor), Tobacco Control, vol. 18, n.o 5, 2009, pp. 358-364; Hoek, Janet; Wilson, Nick; Matthew, Allen et al., "Lessons from New Zealand's introduction of pictorial health warnings on tobacco packaging" (trad. del autor), Bulletin of the World Health Organization, vol. 88, n. ${ }^{\circ} 11,2010$, pp. 861-866. 
de propiedad que no contemplan limitaciones frente a medidas que pretenden justificadamente proteger el interés público ${ }^{43}$.

El caso de Chile se entiende como uno de los más extremos, ya que el estándar de protección no solo considera expropiación la privación del derecho, sino también la afectación de sus atributos esenciales. En efecto, el artículo 19 n. ${ }^{\circ} 24$ de la Constitución señala: "Nadie puede, en caso alguno, ser privado de su propiedad, del bien sobre el que recae o de algunos de los atributos o facultades esenciales del dominio, sino en virtud de ley general o especial que autorice la expropiación por causa de utilidad pública o de interés nacional, calificada por el legislador" ${ }^{\prime \prime 4}$.

Si se considera que lo que constituye el derecho de marca de manera predominante en las legislaciones es el derecho de uso de la misma, la implementación de un empaquetado genérico que prohíba su uso constituiría expropiación y tendría importantes costos asociados; sin embargo, se evidencia claramente en el artículo de la Constitución chilena antes mencionado que se considera que las medidas del empaquetado genérico no transgreden el derecho a ejercer una actividad económica, ni discriminan en el ejercicio de esta, por estimar que las regulaciones en el mercado del tabaco están absolutamente justificadas y apoyadas en razones de salud pública y se enmarcan en el cumplimiento de tratados internacionales suscritos por Chile, como el смст.

En el caso australiano, por el contrario, si bien la legislación sobre marcas confiere el derecho de uso -secc. 20, parte III, Ley de Marcas-, la Corte Suprema estimó que la prohibición del derecho de uso de marca contenida en la ley referida no constituye expropiación porque la Constitución exige una apropiación del derecho por parte del Estado y no una mera afectación o privación del mismo. La apropiación debe importar un beneficio para el Estado. En el caso del empaquetado genérico, si bien se afecta el derecho, no existe una transferencia del dominio para el Commonwealth, por lo que no se trata de expropiación y no requiere de una indemnización correlativa ${ }^{45}$.

Otro ejemplo interesante es el caso alemán, en donde por virtud del artículo 14 de la Constitución se establece una compensación económica para limitaciones o restricciones al derecho de propiedad ${ }^{46}$. Esta se determina sobre la base de

43 Es posible ejemplificar lo anterior con la 5.a enmienda de la Constitución de Estados Unidos, el artículo 28 de la Constitución de Japón, el artículo 17 de la Constitución de Argentina, el artículo 32 de la Constitución de Uruguay y el artículo 70 de la Constitución de Perú.

44 Ver Constitución Política de la República de Chile, Ley 20990, de 22 de septiembre de 2005, Ministerio de Secretaría General de la Presidencia. Disponible en: https://www. leychile.cl/Navegar?idNorma $=242302$

45 DAVISON, MARK, "The legitimacy of plain packaging under international intellectual property law: Why there is no right to use a trademark under either the Paris Convention or the trips agreement”, Faculty of Law, Monash University, Melbourne, Australia, en Mitchell, A.; Voon, T. y Liberman, J. (eds), Public Health and Plain Packaging of Cigarettes: Legal Issues, Edward Elgar, 2012.

46 Ver Ley Fundamental de la República Federal de Alemania, Deutscher Bundestag, de 8 de mayo de 1949, por el Consejo Parlamentario. Disponible en: https://www.btgbestellservice.de/pdf/80206000.pdf 
un balance equitativo entre el interés público y los derechos afectados, por lo que otorga un amplio margen para medidas que se encuentran justificadas en beneficio general de la población.

\subsection{Distintividad MARCARIA ANTE los CONSUMidores}

La aplicación de las medidas de empaquetado genérico a un producto con tales características impedirá la asociación de las marcas a estos rasgos distintivos y por lo tanto anulará su valor comercial en ese territorio, al tiempo que limitará el derecho de los consumidores a decidir por la calidad de un producto asociada a su marca.

Las marcas de tabaco, como cualquier otra marca, cuentan con multiplicidad de caracteres, formas y colores que hacen que, al diferenciarse de las de sus competidoras y asociarse a un concepto implícito y a un público determinado, al consumidor le sea posible elegir una u otra, dependiendo de factores que van más allá del mismo producto, eso es, de la percepción de que la marca es objeto ${ }^{47}$.

Los signos distintivos juegan un papel principal en cualquier mercado relevante, pues informan al consumidor o usuario acerca de la naturaleza de un producto $\mathrm{y} / \mathrm{o}$ servicio, de sus características, sus atributos y su origen; esto facilita la selección entre unos y otros ${ }^{48}$, y aligera su puesta en circulación por parte de los titulares, que ven fortalecida su labor a medida que el signo obtiene reconocimiento.

Si se analiza a partir de las funciones, estas se ven directamente afectadas por las medidas de empaquetado genérico, por lo cual resultan desproporcionadas para el fin que persiguen, pues afectan la distintividad de la marca, al punto de que podría llegar a vulgarizarse; de igual forma, afectarían la decisión de adquisición del consumidor, quien podría verse inducido a un innecesario riesgo de confusión respecto del producto deseado, al incurrir en la posibilidad de escoger aquel que no es de su interés.

Esta función de distintividad constituye la principal ventaja que una marca ofrece a un consumidor, puesto que le permite crear un vínculo entre el producto y el origen empresarial, según su conformidad o inconformidad con la marca del producto de tabaco escogida, lo que facilita las decisiones posteriores respecto a adquirir o no el producto nuevamente, pues ya se conoce la información en la que se basará la elección a partir de la primera experiencia. En otras palabras, si el producto satisfizo los estándares de elección del consumidor, el titular podrá

47 Ver Martínez-Salcedo, Juan Carlos y Vargas-Chaves, Iván, "La afectación de la marca de tabaco por las medidas de empaquetado genérico", Vniversitas, n. ${ }^{\circ} 130$, 2015, Bogotá, p. 242. Disponible en: http://dx.doi.org/10.11144/Javeriana.vj130.amtm 48 BARreda, José, "Algunas anotaciones respecto de los requisitos de registrabilidad de signos según la Decisión 486 de la Comunidad Andina”, en Estudios de Derecho y Propiedad Intelectual: Homenaje a Arturo Alessandri Besa, Rodrigo Velasco-Santelices y Marcos Morales-Andrade (coords.), Santiago de Chile, Jurídica de Chile, 2009, p. 213. 
tener la confianza razonable de que aquel volverá a adquirirlo en el futuro, ya que el consumidor lo asociará con la marca que en un primer momento conoció ${ }^{49}$.

El factor evocativo y la asociación que el consumidor realiza a la hora de elegir le representan la certeza de conocer quién es el fabricante del producto que adquiere. Barreda no duda en sostener que la gran mayoría lo ignora y que, en rigor, esta es una información susceptible de divulgarse en el rotulado del empaque, mas no de la marca ${ }^{50}$. A este respecto, Fernández-Novoa afirma que la marca atestigua ante los consumidores que todos los productos de una misma clase asociados a esa marca provienen de una misma empresa ${ }^{51}$. Así también lo ha admitido el Tribunal de Justicia de la Comunidad Andina (en adelante, TJCAN), para el que las marcas, como medio de protección del consumidor, cumplen varias funciones, destacándose entre aquellas el permitirle al consumidor distinguir los productos o servicios de una empresa ${ }^{52}$.

\subsection{Afectación de otras funciones de las marcas}

Sobre las demás funciones, las medidas de empaquetado genérico también resultan lesivas para atributos como la condensación de goodwill, pues el indicador de buena reputación y prestigio se pierde con el uso de imágenes disuasivas, aunque en este caso coincidamos con su utilidad, que es el fin que se persigue.

Si estas imágenes ocuparan solo una cara de la cajetilla, cuanto menos lograrían transmitir el mensaje deseado, sin que la marca se distorsionara al no perder la visibilidad que ya tiene.

A estos efectos, aquellas medidas que exigen que se ocupen las dos caras en la cajetilla afectan la función publicitaria y de inversión de la marca, lo que evita que el vínculo con el producto se fije en el top of mind del consumidor. A su vez, afecta la recordación, el posicionamiento y la aceptación que pueda tener dentro del público; y merma la posibilidad de que en algún momento adquiera una fuerza sugestiva en sí misma ${ }^{53}$, que permita al consumidor inclinarse por adquirir los productos que identifica.

49 Vargas-Chaves, Iván y Rodríguez-Ramírez, Sara, "La caducidad por vulgarización en la marca y su efecto estabilizador en los mercados", Panorama, n. ${ }^{\circ}$ 13, julio-diciembre, 2013, pp. 127-137. Disponible en: http://papers.ssrn.com/sol3/papers. cfm?abstract_id=2369869

50 BARREDA José, "Algunas anotaciones respecto de los requisitos de registrabilidad de signos según la Decisión 486 de la Comunidad Andina”, en Estudios de Derecho y Propiedad Intelectual: Homenaje a Arturo Alessandri Besa, cit., p. 223.

51 Fernández-Novoa, Carlos, "Signos distintivos. Marcas. Las funciones de las marcas”, en Fernández-Novoa, Carlos, José Manuel Botana Agra y José Manuel Otero Lastres, Manual de la propiedad industrial, Madrid, Marcial Pons, Ediciones Jurídicas y Sociales, 2013, pp. 501-509.

52 Tribunal de Justicia de la Comunidad Andina, TJCAN, Proceso 04-IP-95, GranolaJet vs. República de Colombia - Consejo de Estado, 15 de diciembre de 1997.

53 Fernández-Novoa, ob. cit., p. 591. 


\subsection{IMPLICACIONES EN EL COMERCIO INTERNACIONAL}

Otras implicaciones de estas medidas podrían tener lugar en el comercio internacional, dados los bajos ingresos que obtendrán las administraciones por recaudación de impuestos por venta de tabaco, junto con el riesgo al que se expondrán los consumidores por un previsible aumento de la falsificación transfronteriza de cigarrillos y puros, favorecida por la ausencia de mecanismos de seguridad presentes en las cajetillas, como relieves, hologramas o marcas de agua, que deberán dejarse de utilizar por ser contrarios a las medidas de empaquetado genérico.

A su vez existe la preocupación por el incremento del comercio ilícito de los productos del tabaco, por cuanto será mucho más fácil falsificar el empaque sin el uso distintivo de la marca. En este sentido, la medida que se propone para contrarrestar la falsificación de los productos es a través de un código alfanumérico único, pero tal código puede también ser reproducido en un empaque falso, y además no es evidente el efecto real sobre el consumidor, al cual le seguirá siendo imposible identificar si realmente está consumiendo un producto falso o no.

\subsection{CONSIDERACIONES EN TORNO A LA LEGALIDAD \\ DE LA MEDIDA DE EMPAQUETADO GENÉRICO}

Se estima que los gobiernos deben implementar políticas efectivas para controlar el consumo de tabaco y al mismo tiempo respetar los derechos de las marcas, es decir que se debe buscar un equilibrio entre los derechos de los titulares y los intereses públicos. Sin embargo, el empaquetado genérico no cumple estos criterios, en primer lugar por cuanto elimina la elección del consumidor, interrumpe la competencia en el mercado y, por supuesto, priva de los derechos reconocidos por la propiedad intelectual, como se ha analizado a lo largo de este trabajo.

No obstante, se comparte la importancia de proteger la salud pública y la responsabilidad que tienen los Estados de velar por ello. Sin embargo, continúa siendo una interrogante si Australia consideró o no la posibilidad de aplicar otras medidas menos restrictivas que permitieran alcanzar los mismos objetivos de salud. Sobre todo, teniendo en cuenta que el propio Convenio Marco de la oms para el Control del Tabaquismo en sus artículos 5, 11 y 13 no incluye ninguna disposición que obligue a adoptar el empaquetado genérico, solo recomienda que las partes consideren la adopción del empaquetado neutro para eliminar la publicidad o promoción, incluidas las características de diseño que hace que los productos sean atractivos ${ }^{54}$.

54 Ver Directrices para la aplicación del artículo 13 (Publicidad, promoción y patrocinio del tabaco) del Convenio Marco de la oms para el Control del Tabaco. Disponible en: http://www.who.int/fctc/guidelines/article11es.pdf?ua=1 - http://www.who.int/fctc/ guidelines/article13es.pdf Consultado el 17 de febrero de 2017. 
Se hace necesario contar con evidencia científica que sustente la existencia de un vínculo directo entre la medida y los objetivos de protección a la salud que se propone alcanzar, a la luz del artículo 8 del ADPIC, del cual se ha hecho mención. Además, no existen garantías de protección de los derechos de los titulares según el artículo 16 del ADPIC, ni de asegurar a los titulares de las marcas su protección ante falsificaciones o competencia desleal ${ }^{55}$.

En este sentido, las medidas de empaquetado genérico no son proporcionales y razonables con este doble propósito que el Estado persigue, si se considera que muchas de ellas exigen como condición indispensable para la comercialización de productos de tabaco la inclusión de advertencias generales y adicionales que deben presentarse con un formato predefinido en cuanto al color, el tamaño y el tipo de letra. Ante estas advertencias -fácilmente perceptibles- el consumidor debería ser capaz de prever el riesgo al que se expone.

En consecuencia, una primera apreciación permite deducir que estas exigencias no son suficientes para alcanzar y salvaguardar el derecho a la salud. Además, quizás medidas menos restrictivas podrían ser el mecanismo idóneo, al no afectar el derecho a la propiedad intelectual ${ }^{56}$. Sin embargo, las medidas no solo exigen la inclusión de las advertencias antes referidas; por el contrario, van mucho más allá, al limitar por completo el uso de la marca en el mercado relevante.

Una segunda apreciación permite aproximarse de manera más serena a la realidad que aqueja a los titulares de marcas de esta industria, pues, si bien estas medidas están fundadas en un legítimo objetivo, ni se les garantiza el goce de sus derechos, ni tampoco se garantiza la proporcionalidad de estas ${ }^{57}$.

\section{Conclusiones}

El rol actual de las marcas en el mundo económico-empresarial sigue siendo clave a la hora de diferenciar los productos y empresas de sus competidores. Así, el valor estratégico que desempeñan esos derechos de propiedad industrial aumenta ante el nuevo contexto global de la hipercompetitividad.

La adopción de las medidas de empaquetado genérico no es proporcional al fin perseguido, lo que afecta los legítimos intereses del titular de una marca de tabaco, pues aún no está demostrado que los beneficios reportados en la salud de los consumidores sean mayores que los efectos generados sobre aquellos.

55 Cuba, Honduras, Indonesia, Nicaragua, República Dominicana, Ucrania y Zimbabwe reiteraron su apoyo a los objetivos que se persiguen en materia de salud, pero mostraron de nuevo su preocupación por la posibilidad de que se infrinja el ADPIC, al impedir que los productores usen marcas de fábrica o de comercio e indicaciones geográficas.

56 Caminero-Carvajal, Leticia, "Posibles implicaciones legales en el derecho marcario dominicano por la adopción de medidas de empaquetado genérico en los productos de tabaco", Revista Especializada Gaceta Judicial, 63, diciembre de 2012. Disponible en: http://www.central-law.com/template/dmk-pdf/Art\%C3\%ADculo-PI-Leticia-CamineroLey-del-Tabaco-en-RDMarzo-2013.pdf

57 Ibíd. 
Estas medidas son totalmente incompatibles con el ADPIC y con otras obligaciones internacionales adquiridas respecto de la protección marcaria. Como consecuencia, algunos Estados han expresado su inconformidad frente al empaquetado genérico y han acudido al sistema de solución de controversias de los diferentes organismos internacionales, como el de la oMC, para perseguir el incumplimiento de otros Estados, como Australia, al acoger las citadas recomendaciones del СMCT sobre el empaquetado genérico en su derecho nacional.

Aun cuando el propósito de las medidas de empaquetado genérico reivindica la salud como un derecho que debe ser protegido por el Estado, por ser de interés general, estas medidas contribuyen a la pérdida de los atributos y funciones propias de las marcas, con lo cual podrían favorecer en el consumidor la configuración de un riesgo de confusión e, incluso, quebrantar el acceso al mercado de los competidores.

El empaquetado genérico es una medida demasiado drástica para perseguir el objetivo de la protección de la salud, pues puede facilitar y abaratar las falsificaciones y conllevar un aumento del consumo de tabaco. Al igual que ocurre con la adopción de medidas similares para otros productos, como aquellos con un alto contenido de azúcar, grasa y alcohol.

La legalidad del empaquetado genérico ya se está revisando en diversos foros y jurisdicciones. Aunque la demanda es siempre el último recurso, existen países que se oponen a aquel por la responsabilidad que les asiste de proteger sus marcas.

Se desprende entonces que, si bien la evidencia preliminar sobre la efectividad de las advertencias gráficas en dimensiones significativas o de un eventual empaquetamiento genérico es aún controvertida, probar el vínculo causal entre el empaquetamiento genérico y la protección de la salud pública, e invocar exitosamente la aplicabilidad del artículo 8(1) del ADpic, es perfectamente viable. Pero también será una tarea ardua.

No hay evidencia empírica, en Chile o en el extranjero, que vincule el empaquetado genérico con una elevada disminución del consumo. Muy por el contrario, un año y medio después de la aplicación del empaquetado genérico en Australia, funcionarios de ese gobierno revelaban a la prensa que el valor del gasto total en tabaco había disminuido, pero que el volumen de ventas había aumentado. Ambos resultados son compatibles, pues se explican por el menor precio del tabaco. La disminución sostenida del consumo de tabaco en Australia se revirtió cuando el empaquetado genérico impidió el uso de las respectivas marcas. 


\section{BibliografíA}

\section{LIBROS Y REVISTAS}

Arana Courrejolles, María del Carmen, "La no distintividad marcaria", Derecho y Sociedad, n. ${ }^{\circ}$ 36, Asociación Civil, 2014.

BARredA, José, "Algunas anotaciones respecto de los requisitos de registrabilidad de signos según la Decisión 486 de la Comunidad Andina”, Estudios de Derecho y Propiedad Intelectual: Homenaje a Arturo Alessandri Besa, pp. 213-244.

Baylos Corroza, Hermenegildo, Tratado de Derecho Industrial, Madrid, Civitas, 1970 .

Bercovitz Rodríguez-Cano, A., Introducción a las marcas y otros signos distintivos en el tráfico económico, Pamplona, Aranzadi, 2002.

Borland, R.; Wilson, N.; Fong et. al., "Impact of graphic and text warnings on cigarette packs: Findings from four Countries over five years", Tobacco Control, vol. 18, n. ${ }^{\circ}$ 5, 2009, pp. 358-364.

Browne, Jaron; Hennessey-Lavery, Susana y Rogers, Kim, "Valen más que mil palabras. Las etiquetas de advertencias pictóricas de tabaco y los derechos lingüísticos de Estados Unidos", Power, Tobacco Free Coalition, Data Center, 3-20, 6, Series Reports on Industry Activity from Outside, University of California, San Francisco, Center for Tobacco Control Research and Education, 2007. Disponible en: https:/escholarship.org/uc/item/1db2x4wn

Caminero-Carvajal, Leticia, "Posibles implicaciones legales en el derecho marcario dominicano por la adopción de medidas de empaquetado genérico en los productos de tabaco", Revista Especializada Gaceta Judicial, 63, diciembre de 2012. Disponible en: http://www.central-law.com/template/dmk-pdf/ Art\%C3\%ADculo-PI-Leticia-Caminero-Ley-del-Tabaco-en-RDMarzo-2013. pdf

CÁndano Pérez, Mabel, "Protección constitucional de los derechos intelectuales. Especial referencia a Cuba”, tesis presentada para oprtar al grado de máster en Gestión de la Propiedad Industrial, OcPi, Cuba, 2016.

Cifuentes Castro, Andrés Felipe, “Lain packaging: controversias alrededor de las restricciones al uso de marcas registradas vinculadas a los productos del tabaco", Revista de Derecho Privado, n. ${ }^{\circ}$ 53, enero, 2015, pp. 266-290.

Culliton-González, Katherine, "The impact of alcohol and tobacco advertising on the Latino Community as a Civil Rights issue", Berkeley La Raza Law Journal, 16, 2005. Disponible en: http://works.bepress.com/katherine_culliton/2/

DAVISON, MARK, "The legitimacy of plain packaging under international intellectual property law: Why there is no right to use a trademark under either the Paris Convention or the trips agreement", Faculty of Law, Monash University, Melbourne, Australia, en Mitchell, A. D.; Voon, T. y Liberman, J. (eds.). Public Health and Plain Packaging of Cigarettes: Legal Issues, Edward Elgar, 2012. 
Fernández-Novoa, Carlos, Fundamentos de derechos de marcas. Madrid, Montecarlo, 1984.

Fernández-Novoa, Carlos, Tratado sobre derecho de marcas, 2. ${ }^{a}$ ed., Madrid y Barcelona, Marcial Pons y Ediciones Jurídicas y Sociales, 2004.

Fernández-Novoa, Carlos; Botana-Agra, José Manuel y Otero-Lastres, José Manuel, Manual de la propiedad industrial, Madrid, Marcial Pons, 2009.

Fisk, Catherine, "Removing the 'Fuel of Interest' from the 'Fire of Genius': Law and the Employee-Inventor, 1830-1930", University of Chicago Law Review, vol. 65, n. ${ }^{\circ}$ 4, 1998.

Gil Albinader, Luis, "El empaquetado genérico de cigarrillos y la propiedad intelectual", Puentes, vol. 12, n. ${ }^{\circ} 4$, ICTSD, 3 de noviembre de 2011.

Hoek, Janet; Wilson, Nick; Allen, Matthew et al., "Lessons from New Zealands introduction of pictorial health warnings on tobacco packaging", Bulletin of the World Health Organization, vol. 88, n. ${ }^{\circ}$ 11, 2010, pp. 861-866.

Hunt, Paul, "The right to everyone to the enjoyment of the highest attainable standard of physical and mental health", United Nations, Economic and Social Council, Commission on Human Rights, Report of the Special Rapporteur, Paul Hunt, Submitted in accordance with Commission Resolution 2002/31, E/CN. 4/2003/58, 13/02/2003, n. ${ }^{\circ} 15$ y 20.

Husten, C.; Jackson, K. y Lee, C., "Cigarette smoking among adults - United States 2002", Morbidity and Mortality, Weekly Report, 53, 20, 2004, pp. 427431. Disponible en: http://www.ncbi.nlm.nih.gov/pubmed/15163928 - http:// www.cdc.gov $/ \mathrm{mmwr} /$ preview $/ \mathrm{mmwrhtml} / \mathrm{mm} 5320 \mathrm{a} 2 . \mathrm{htm}$

Liberman, Jonathan, "Plainly Constitutional: The Upholding of Plain Tobacco Packaging by the High Court of Australia", American Journal of Law \& $\mathrm{Me}$ dicine, 39, 2013, pp. 361-381. Disponible en: http://papers.ssrn.com/sol3/ papers.cfm?abstract_id $=2215346$

Lou Lee, Betty, "Sell tobacco in no-frills wrappers, urge doctors", The Journal of the Addiction Research Foundation, 15, 10, 1-5, 1986.

Martínez-Salcedo, Juan Carlos y Vargas-Chaves, Iván, "La afectación de la marca de tabaco por las medidas de empaquetado genérico", Vniversitas, n. ${ }^{\circ} 130$, Bogotá, 2015. Disponible en: http://dx.doi.org/10.11144/Javeriana.vj130.amtm

Monteagudo Monteano, "La protección de la marca renombrada, y riesgos de confusión en el derecho de marcas y derecho contra competencia desleal", Actas de Propiedad Industrial, n. ${ }^{\circ}$ 15, Madrid, Civitas, 1995.

Otamendi, Jorge, Derecho de marcas, Buenos Aires, Argentina, Abeledo-Perrot, 2010.

Robles Morchón, Gregorio, Marcas en el derecho español, Madrid, Civitas, 1995. Rodríguez, Gloria Amparo y PÁez-PÁez, Iván Andrés, "Las medidas preventivas ambientales, una aproximación desde el derecho administrativo", Opinión Jurídica, vol. 23, n. ${ }^{\circ}$ 17, enero-junio de 2013, pp. 17-30. Disponible en: http:// revistas.udem.edu.co/index.php/opinion/article/view/563. 
Sandoval López, Ricardo, Marcas comerciales, Santiago, Jurídica de Chile, 2006. Schotz, Gustavo J. et al., Patentes y medicinas esenciales. La armonización entre el derecho a la salud y la propiedad intelectual, Buenos Aires, Heliasta.

Stephen Williams, "The More Law, the Less Rule of Law", The Green Bag an Entertaining Journal of Law, 2, 4, 1999, pp. 403-409. Disponible en: http:// www.greenbag.org/v2n4/v2n4_articles_williams.pdf

Tenorio, Luis Felipe, "Cigarrillos y malteada de chocolate: la Tobacco Plain Packaging Act australiana de 2011", Criterio Jurídico, 12, 2, 2012, pp. 151-180. Disponible en: http://revistas.javerianacali.edu.co/index.php/criteriojuridico/ article/download/624/823

Troller, Kamen, Précis du droit suisse des biens inmatériels, Helbing \& Lichtenhahn, 2001.

Vargas-Chaves, Iván y Rodríguez-Ramírez, Sara, "La caducidad por vulgarización en la marca y su efecto estabilizador en los mercados", Panorama, 13, julio-diciembre de 2013, pp. 127-137. Disponible en: http://papers.ssrn.com/ sol3/papers.cfm?abstract_id=2369869

Velásquez, G.; Correa, C. y Seuba, X., IPR, R\&D, Human Rights and Access to Medicines: An Annotated and Selected Bibliography, South Centre, Geneva, 2012.

Yves Saint-GaL, Protección y defensa de las marcas de fábrica y concurrencia desleal, París, Delmas, 1982.

\section{LEGISLACión}

Constitución Política de la República de Chile, Ley 20.990, de 22 de septiembre de 2005, Ministerio de Secretaría General de la Presidencia. Disponible en: https://www.leychile.cl/Navegar?idNorma=242302

Convenio de París para la Protección de la Propiedad Industrial, de 20 de marzo de 1883. Disponible en: http://www.wipo.int/treaties/es/text.jsp?file_id=288515

Diario Oficial de las Comunidades Europeas, DOCE, 18 de julio de 2001. Disponible en: http://ec.europa.eu/health/tobacco/docs/dir200137ec_tobaccoproducts_es.pdf

Ley Fundamental de la República Federal de Alemania, Deutscher Bundestag, de 8 de mayo de 1949, por el Consejo Parlamentario. Disponible en: https://www. btg-bestellservice.de/pdf/80206000.pdf

Ley 20.660, de 1 de marzo de 2013, del Ministerio de Salud, Subsecretaría de Salud Pública. Disponible en: http://www.leychile.cl/Navegar?idNorma=1047848

Organización Mundial de la Salud, oms, Convenio Marco para el Control del Tabaco, Organización Mundial de la Salud, oms, Ginebra, 1 de mayo de 2003. Disponible en: http://www.who.int/tobacco/framework/wHo_fctc_spanish.pdf Organización Mundial del Comercio, омC (wTo), Acuerdo sobre los Aspectos de los Derechos de Propiedad Intelectual relacionados con el Comercio, ADPIC. Disponible en: https://www.wto.org/spanish/docs_s/legal_s/27-trips_01_s.htm 
Organización Mundial del Comercio, OMC (wTO), Solución de Controversias DS441: determinadas medidas relativas a las marcas de fábrica o de comercio, indicaciones geográficas y otras prescripciones de empaquetado genérico aplicables a los productos de tabaco, Velasco-Santelices, R. y Morales-Andrade, M. (coords.), Santiago, Jurídica de Chile, 2009.

República de Cuba. Decreto-Ley n. ${ }^{\circ} 203$, de marcas y otros signos distintivos, de 24 de diciembre de 1999, Gaceta Oficial Extraordinaria n. ${ }^{\circ} 31,2000$.

Tobacco Plain Packaging Act, n. ${ }^{\circ} 148,2011$, An Act to discourage the use of tobacco products, and for related purposes. Disponible en: http://www.wipo.int/wipolex/ es/text.jsp?file_id=271351

Unión Europea, UE, Directiva 2001/37/CE del Parlamento y del Consejo, relativa a la aproximación de las disposiciones legales, reglamentarias y administrativas de los Estados Miembros en materia de fabricación, presentación y venta de los productos del tabaco, de 5 de junio de 2001.

\section{JURISPRUDENCIA}

High Court of Justice Queen's Bench Division (Administrative Court). Sentencia del Tribunal de Justicia, Sala Segunda, de 4 de mayo de 2016. Asunto: C-547/14. Partes: Philip Morris Brands SARL y otros c. Secretary of State for Health. Disponible en: http://eur-lex.europa.eu/legal-content/ES/ TXT/?uri=CELEX:62014CJ0547

Juzgado de lo Mercantil n. ${ }^{\circ}$ 8, Madrid. Sentencia n. ${ }^{\circ} 84 / 2015$, Recurso de apelación 260/13. Disponible en: http://www.poderjudicial.es/search/doAction?ac tion $=$ contentpdf\&databasematch $=$ AN\&reference $=7354584 \&$ links $=\&$ optimi ze $=20150422 \&$ publicinterface $=$ true

Tribunal de Justicia de la Comunidad Andina, TJCAn, Proceso 04-IP-95, GranolaJet vs. República de Colombia - Consejo de Estado, 15 de diciembre de 1997. 